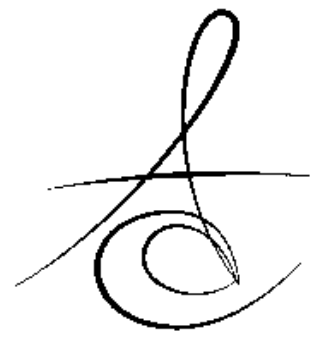

\title{
KİMYASAL TEMİZLEYİCİLERİN AKRİLİK DİŞLERİN YÜZEY SERTLİKLERİNE ETKİSí
}

EFFECT OF CHEMICAL CLEANSERS ON THE SURFACE HARDNESS OF ACRYLIC DENTURE TEETH

Yrd. Doç. Dr. Orhun EKREN*

Doç. Dr. Ahmet ÖzKöMÜR**

Makale Kodu/Article code: 1811

Makale Gönderilme tarihi: 01.08.2014

Kabul Tarihi: 20.10.2014

\section{ÖZET}

Amaç: Bu çalışmanın amacı 3 farklı kimyasal protez temizleyicisinin akrilik dişlerin yüzey sertliğine etkisini araştırmaktır.

Materyal ve Metod: İki farklı markaya ait akrilik takım dişlerin premolar ve molar dişleri soğuk akrile oküzal yüzeyleri üstte kalacak şekilde gömüldü. Dişlerin oklüzal yüzeyleri zımpara ile düzleştirildi ve polisajlandı. Hazırlanan örnekler üç farklı kimyasal temizleyici (Protefix, Corega Tabs ve \%1 $\mathrm{NaOCl}$ ) ve kontrol grubu olarak distile su içerisine tesadüfi olarak yerleştirildi. Test örnekleri kimyasal temizleyicilere günde 8 saat olmak üzere bir hafta boyunca maruz bırakıldı. Bu sürenin sonunda örnekler Knoop sertlik testine tabi tutuldu. Verilerin istatiksel analizleri tek yönlü ANOVA ve Tukey testleri kullanılarak gerçekleştirildi.

Bulgular: Vitapan dişlerin Knoop sertlik değerleri tüm gruplarda Major Dent gruplarına göre yüksek bulundu. Çalışmada test edilen kimyasal temizleyicilerin protez dişlerinin Knoop sertlik değerlerinde istatistiksel olarak anlamlı değişikliklere neden olmadığı görülmüştür.

Sonuç: Çalışmanın sınırları içerisinde test edilen kimyasal temizleyicilerin test edilen akril dişlerin yüzey sertliklerine negatif etkisinin olmadığı gösterilmiştir.

Anahtar Kelimeler: Protez temizleyicileri, Yapay dişler, Sağlamlık testleri

\section{ABSTRACT}

Aim: The aim of this study was to investigate the effect of three chemical denture cleansers on the Knoop hardness of the acrylic denture teeth.

Material and Method: Premolar and molar acrylic denture teeth from two manufacturers were embedded in cold cured acrylic resin. The occlusal surfaces of teeth were flat grounded and polished. The specimens were randomly divided into 4 groups and immersed in three different chemical disinfection (Protefix, Corega Tabs and \%1 $\mathrm{NaOCl}$ ) and distilled water (Control group) for 8 hours/day during 7 days. The specimens were submitted to Knoop hardness measurements immediately after disinfection procedures. Data were analyzed with one way ANOVA and Tukey's statistical test.

Result: All Vitapan group exhibited higher Knoop hardness values than Major Dent groups both in control and experimental groups. The tested chemical denture cleaning methods did not show any significant effect on Knoop hardness of the artificial teeth.

Conclusion: Within the limitations of this study it can be concluded that exposure of artificial teeth to chemical disinfectants did not affect the hardness of the acrylic teeth.

Key Words: Denture cleansers, Artificial teeth, Hardness

\footnotetext{
*Çukurova Üniversitesi Diş Hekimliği Fakültesi, Protetik Diş Tedavisi A.D

** Pontıfıcıa Unıversıdade Catolıca Do Rıo Grande Do Sul Diş Hekimliği Fakültesi, Protetik Diş Tedavisi A.D
} 


\section{GİRIŞ}

Akrilik protezlerin temizliği, protez stomatitisinin engellenmesinde ve ağız mukozası sağığının korun masında çok önemlidir. ${ }^{1-3}$ Diş hekimleri hastalarına protezlerin günlük temizliğini lavabo başında sabun ve fırça kullanarak nasıl yapacaklarını anlatır. Ancak bedensel ve/veya akli melekeleri azalmış bireyler bu basit temizliği bile yapamayabilir. ${ }^{4,5} \mathrm{Bu}$ gibi durumlarda kimyasal temizleyiciler hayat kurtarıcıdır. Günümüzde kimyasal protez temizleyicileri protez kullanıcıları tarafından sıklıkla kullanılmaktadır ve etkinlikleri farklı çalışmalarda gösterilmiştir. ${ }^{6-8}$ Kimyasal temizleyiciler asıl kullanım amaçları olan bakterisidal, fungisidal etki göstermelerinin ve protezin üzerinde birikmiş kalıntıları temizleyebilmelerinin yanı sıra protezin mekanik ve fiziksel özelliklerini etkilememelidirler.

Sertlik, materyalin indentasyona gösterdiği direnç olarak tanımlanır. Materyallerin aşınmaya karşı dirençleri sertliklerine bakılarak tahmin edilebilmektedir. ${ }^{9,10}$ Sertlik testleri protez dişlerinin aşınmaya dirençlerini test etmede en çok kullanılan yöntemdir. ${ }^{9}$ Akrilik protez dişlerin aşınmaya karşı dirençli olması, protezlerin uzun dönem başarısı için önemlidir. Okluzal yüzeylerin aşınması vertikal yüz yüksekliğinin, çiğneme kaslarının etkinliğinin azalmasına, estetik ve temporomandibular eklemde problemlere neden olabilir. ${ }^{11-14}$

$\mathrm{Bu}$ çalışmanın amacı üç farklı kimyasal temizleyicinin, iki farklı akrilik dişin sertlikleri üzerine etkisini araştırmaktır.

\section{MATERYAL VE METOD}

Çalışmada kullanılan kimyasal dezenfektanlar ve akrilik dişler Tablo I'de gösterilmiştir.

Yüzey sertlik testi için akrilik premolar ve molar dişler kullanılmıştır. Dişler oklüzal yüzeyleri yukarıda olacak şekilde şeffaf akrilik içerisine yerleştirilerek her grup için 8 adet olacak şekilde toplam 64 adet test örneği hazırlanmıştır. Polimerizasyon sonrası akrilik dişlerin oklüzal yüzeyleri düz bir yüzey oluşana kadar zımparalanmıştır. Zımparalanan yüzeyler polisaj cihazında 2000 grit SiC zımpara kağıdı ve $1 \mu^{\prime}$ luk alumina solusyonu ile parlatılmıştır (Resim1).
Tablo 1. Çalışmada kullanılan materyaller.

\begin{tabular}{|c|c|c|}
\hline Materyal & Üretici & İçerik \\
\hline $\begin{array}{l}\text { Corega } \\
\text { Tabs }\end{array}$ & $\begin{array}{l}\text { Block Drug } \\
\text { Company, Inc., } \\
\text { New Jersey, ABD }\end{array}$ & $\begin{array}{lr}\text { Potasyum } & \text { monopersülfat, } \\
\text { Sodyum } & \text { bikarbonat, } \\
\text { Sodyum } & \text { perborat } \\
\text { monohidrat, } & \text { Sodyum } \\
\text { fosfat } & \\
\end{array}$ \\
\hline Protefix & $\begin{array}{l}\text { Queisser } \\
\text { Pharma, } \\
\text { Flensburg, } \\
\text { Almanya }\end{array}$ & $\begin{array}{l}\text { Sodyum bikarbonat, } \\
\text { Potasyum karoat, Sodyum } \\
\text { perborat, Sitrik asit, } \\
\text { Sodyum sülfat, Aroma }\end{array}$ \\
\hline $\begin{array}{l}\text { \%1 } \\
\mathrm{NaOCl}\end{array}$ & $\begin{array}{l}\text { Cleanday, Trakya } \\
\text { Ticaret, } \\
\text { Edirne, Türkiye }\end{array}$ & $\begin{array}{ll}\text { Sodyum } & \text { Hipoklorit } \\
\text { solüsyonu } & \end{array}$ \\
\hline $\begin{array}{l}\text { Majör } \\
\text { dent }\end{array}$ & $\begin{array}{lr}\text { Major } & \text { Prodotti } \\
\text { Dentari } & \text { S.p.A, } \\
\text { Ittalya } & \\
\end{array}$ & Polimetilmetakakrilat \\
\hline Vitapan & $\begin{array}{l}\text { VITA Zahnfabrik } \\
\text { GmbH \& Co. } \\
\text { KG, Almanya }\end{array}$ & $\begin{array}{l}\text { Mikro dolduruculu } \\
\text { Polimetilmetakakrilat }\end{array}$ \\
\hline
\end{tabular}
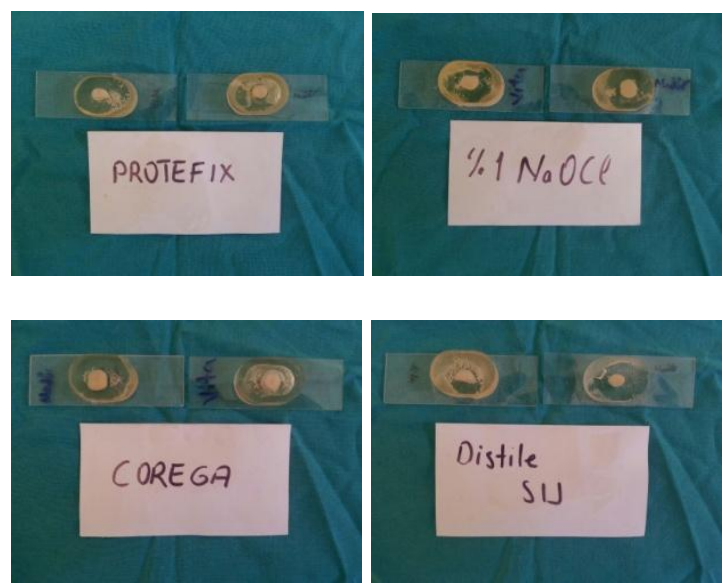

Resim 1. Yüzey hazırlığı tamamlanmış akrilik dişler

Yüzey polisajı tamamlanan test örnekleri kimyasal dezenfektanlara ve kontrol grubu olarak distile su içerisine yerleştirilmiştir. Günde 8 saat olmak üzere 1 hafta boyunca kimyasal solüsyonlara maruz bırakılmıştır. Her 8 saat sonunda test örnekleri distile su içerisinde bekletilmiş ve her defasında yeni kimyasal solüsyon hazırlanmıştır. Bir haftalık süre sonunda örnekler akarsu altında yıkanarak hava spreyi ile kurutulmuştur. Hazırlanan örneklerin Knoop sertlik numarası (KHN) ölçümleri dijital mikro-sertlik test cihazında (Buehler MMT-3, Waukagen Lake Bluff, IL, USA) yapılmıştır. Test cihazının ucu örneklere $15 \mathrm{sn}$ boyunca 100 gf kuvvet uygulamıştır. Her örnekten 3

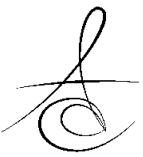


farklı noktadan sertlik ölçümü yapılmışır. Sertlik ölçümlerinin aritmetik ortalaması o örneğin Knoop sertlik değeri olarak kaydedilmiştir. Veriler, tek yönlü ANOVA ve Tukey posthoc istatistiksel test yöntemleri kullanılarak SPSS 15.0 programinda analiz edilmiştir.

\section{BULGULAR}

Kimyasal temizleyicilere maruz bırakılan akrilik dişlerin ortalama KHN değerleri Tablo 2'de verilmiştir.

Tablo 2. Gruplara ait ortalama KHN değerleri ve standart sapmaları

\begin{tabular}{|l|l|l|l|l|l|}
\hline & Kontrol & Protefix & Corega & \%0.1NaOCI & $*$ \\
\hline Major & 16,40 & 15,84 & 15,14 & $16,85(0,87)$ & 15,81 \\
& $(1,62)$ & $(0,96)$ & $(0,93)$ & & $(1,11) \mathrm{A}$ \\
\hline Vita & 21,25 & 22,46 & 22,12 & $22,02(1,37)$ & 21,95 \\
& $(0,76)$ & $(1,03)$ & $(0,56)$ & & $(1,01) \mathrm{B}$ \\
\hline & \multicolumn{7}{|l|}{ Tek yönlü Anova \& Tukey $(\mathrm{p}<.05)$} & $\begin{array}{l}\text { T-test } \\
\end{array}$ \\
\hline
\end{tabular}

*Farklı harfler istatistiksel olarak anlamlı fark ifade eder.

Mikro dolduruculu akrilik dişlerin KHN (Vitapan) değerleri tüm gruplarda daha yüksek bulunmuştur ( $p$ $<$.0001). Tüm test gruplarında KHN değerlerinde kontrol gruplarına göre istatistiki olarak anlamlı fark görülmemiştir $(p<.05) . \% 0.1$ lik $\mathrm{NaOCl}$ ile diğer protez dezenfektanları arasında istatistiki fark görülmemiştir.(Şekil 1)

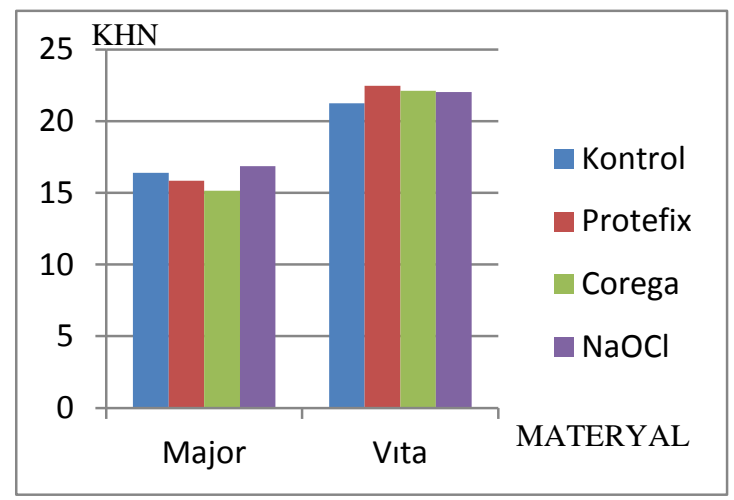

Şekil 1.

\section{TARTIŞMA}

Protez temizliğinde en sık tercih edilen yöntem protezin akarsu altında sabun ile firçalayarak temizlenmesidir. ${ }^{14}$ Günlük olarak yapılması gerekli bu temizlik ağız mukoza sağlığının korunmasında ve fırsatçı enfeksiyonların engellenmesinde çok önemlidir. Ancak bu işlem manipülasyon yeteneği gerektirir. Bu nedenle yaşı ilerlemiş bireyler protez temizliğinde kimyasal temizleyicilere intiyaç duyabilir. ${ }^{15}$ Ayrıca bu kimyasal ajanlar protez üzerinde biriken diş taşı ve lekeleri de etkili biçimde giderebildiklerinden günlük protez temizliğini yapabilen hastalar tarafından da tercih edilmektedir. Çalışmamızda Türkiye pazarında kolaylıkla bulunabilen iki farklı ticari kimyasal temizleyici ve $\% 0.1$ oranında seyreltilmiş çamaşır suyu (sodyum hipoklorid) kullanılmışır. Çamaşır suyu çok etkili bir dezenfektandır. ${ }^{16}$ Yapılan çalışmalarda \%0.05 - 1 aralığında değişen konsantrasyonlarda etkili olduğu ve protez dezenfeksiyonunda kullanılabileceği bildirilmiştir. ${ }^{16-18}$ Ancak estetik problemlere yol açabilecek beyazlatıcı etkisinden söz eden ve protezin yüzey özelliklerini değiştirdiğini bildiren çalışmalar da mevcuttur. ${ }^{17,19}$ Araştırmacılar çamaşır suyunun kolay erişilebilir ve ekonomik olmasından dolayı protez hastaları tarafından hala tercih edildiğini düşünmektedir. Bu nedenle çamaşır suyu çalışmaya dahil edilmiştir.

Üretici firmalar protezlerin rutin temizliğinde kimyasal temizleyicilerde 15 dakika kadar bırakılmasını tavsiye etmektedir. Ancak ağır lekelenmelerde protezlerin temizlenmesi için tüm gece solüsyonda bekletilmesi önerilmektedir ki bu süre yaklaşık 8 saattir. Bu çalışmada kimyasal protez temizleyicilerin etkisini değerlendirebilmek için önerilen sürenin maksimumunu kullanılmışıır.

Dental markette akrilik kaideli protezlerde kullanılmak üzere farklı yapıda yapay dişler bulunmaktadır. Bunlardan en sık kullanılan polimetilmetakrilat (PMMA) yapıda olanlarıdır. ${ }^{20}$ Üretici firmalar yapay dişlerin dayanımlarını artırmak için polimetakrilat içerisine mikrodoldurucular eklemek, polimeri çift çapraz bağlamak (double-crossed linked) veya dişleri komposit resinlerden üretmek vs. gibi yöntemler geliştirmişlerdir. Ancak mekanik dayanımdaki bu artış yapay dişlerin fiyatlarına da yansımaktadır. Fiyatlarındaki bu artış hekimlerin tercihini de etkilemektedir. Çalışmamızda kullanılan yapay dişlerden biri (Majör dent) çapraz bağı PMMA yapısında, diğeri (Vitapan) ise mikro doldurucu eklenmiş çapraz bağlı PMMA yapıdadır. Ürünler uygun fiyatperformans oranı nedeniyle çalışmanın planlandığı klinikte en çok tercih edilen yapay dişlerdir.

Polimerlere silika, quartz gibi inorganik doldurucular eklenerek mekanik özelliklerinin artması

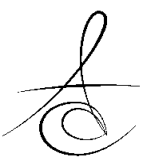


sağlanabilir. ${ }^{21}$ Sertlik ve aşınmaya karşı direnç arasında direk bir ilişki bulunmaktadır. Sertlik arttıkça aşınmaya karşı dirençte artmaktadır. Çalışmamızda mikro doldurucu eklenmiş dişlerin KHN değerleri mikro doldurucu içermeyen dişlere oranla daha yüksek bulunmuştur. Bu sonuç literatürdeki diğer çalışmalar ile uyumludur. ${ }^{12,22,23}$

Polimerizasyon derecesi, çapraz bağlantı yoğunluğu, molar kütle dağılımı da polimerlerin mekanik ve fiziksel özellikleri üzerinde etkilidir. ${ }^{21}$ Özellikle optimal çapraz bağlantı yoğunluğu akrilik rezinlere termal, kimyasal direnç kazandırır. Çapraz bağlantı yapmayan lineer veya yeterli çapraz bağlantı yapmayan akrilik rezinler sulu ortama maruz bırakıldıklarında su emebilir. ${ }^{24}$ Absorbe edilen su polimer zincirleri arasına girerek yapıyı yumuşatabilir. Çalışmada kullanılan akrilik dişler çapraz bağlantılı PMMA polimeridir. Kimyasal temizleyicilerin akrilik dişlerin sertliklerinde azalmaya neden olmaması dişlerin yapımında kullanılan polimerin yeterince çapraz bağ içerdiğini göstermektedir.

Literatürde yapay dişlerin farklı kimyasal solüsyonlarda ve değişen sürelerde farklı mekanik ve fiziksel davranışlar sergilediği çalışmalar mevcuttur. Campanha ve $a k^{25}$. beş farklı akrilik dişi farklı kimyasal solüsyonlara maruz bırakmış ve çalışma sonunda test örneklerin bazı gruplarında yüzey sertliğinde azalma meydana gelirken bazı gruplarda yüzey sertliğinde değişim olmadığını bildirmiştir. Benzer bir çalışmada, Pavarina ve $\mathrm{ark}^{26}$. farklı dezenfeksiyon solüsyonlarının akrilik dişlerin yüzey sertliklerine etkisinin olmadığını bildirmiştir. Bahsi geçen yazarlar test edilen dişlerin kimyasal solüsyonlara dirençli veya zayıf olmalarını polimerlerin çapraz bağlı olup olmamasına ve çapraz bağların yoğunluklarına bağlamışlardır. Uzun dezenfeksiyon süresine rağmen çapraz bağlı yapı kimyasal solüsyonlara direnç göstermiş ve örneklerin yüzey sertliklerinde kontrol grubuna göre anlamlı değişim görülmemiştir.

\section{SONUÇ}

Çalışmanın sınırları dahilinde, protez temizliğinde kullanılan kimyasal temizleyicilerin test edilen akril dişlerin yüzey sertliklerine etkisinin olmadığı gösterilmiştir. Ancak kimyasal temizleyicilerde uzun süreli dezenfeksiyonun protez kaidesine ve kaideakrilik diş bağlantısına etkilerinin de araştırılması gerekmektedir.

\section{KAYNAKLAR}

1. Andrucioli MC, Macedo LD, Panzeri H, Lara EH, Paranhos F. Comparison of two cleansing pastes for the removal of biofilm from dentures and palatal lesions in patients with atrophic chronic candidiasis. Braz Dent J 2004;15:220-4.

2. Pereira-Cenci T, Del Bel Cury AA, Crielaard W, Ten Cate JM. Development of Candida-associated denture stomatitis: new insights. J Appl Oral Sci 2008; 16:86-94

3. Pinto TM, Neves AC, Leão MV, Jorge AO. Vinegar as an antimicrobial agent for control of Candida spp. in complete denture wearers. J Appl Oral Sci 2008;16:385-90.

4. Pietrokovski J, Azuelos J, Tau S, Mostavoy R. Oral findings in elderly nursing home residents in selected countries: oral hygiene conditions and plaque accumulation on denture surfaces. J Prosthet Dent 1995;73:136-41.

5. Pietrokovski J, Levy F, Azuelos J, Tau S, Tamari I, Mostavoy $\mathrm{R}$. Oral findings in elderly nursing home residents in selected countries. 2. Soft tissue lesions and denture wearing habits. Gerodontology 1990;9:75-81.

6. Uludamar A, Ozkan YK, Kadir T, Ceyhan I. Invivo efficacy of alkaline peroxide tablets and mouthwashes on Candida albicans in patients with denture stomatitis. J Appl Oral Sci 2010;18:291-6.

7. Işeri $U$, Uludamar A, Ozkan YK. Effectiveness of different cleaning agents on the adherence of Candida albicans to acrylic denture base resin. Gerodontology 2011;28:271-6.

8. Nalbant AD, Kalkanci A, Filiz B, Kustimur S. Effectiveness of different cleaning agents against the colonization of Candida spp and the in vitro detection of theadherence of these yeast cells to denture acrylic surfaces. Yonsei Med J 2008;49:647-54.

9. Akova T, Ozkomur A, Uysal H. Effect of foodsimulating liquids on the mechanical properties of provisional restorative materials. Dent Mater 2006;22:1130-4.

10. Yeşil Duymuş Z, Kavrut R. Değişik sabit protez estetik materyallerinin sertlik özellikleri yönünden incelenmesi. Atatürk Üniv Diş Hek Fak Derg 2003;13:21-7. 
11. Whitman DJ, McKinney JE, Hinman RW, Hesby RA, Pelleu GB Jr. In vitro wear rates of three types of commercial denture tooth materials. J Prosthet Dent 1987;57:243-6.

12. Lindquist TJ, Ogle RE, Davis EL. Twelve-month results of a clinical wear study of three artificial tooth materials. J Prosthet Dent 1995;74:156-61.

13. Winkler S, Monasky GE, Kwok J. Laboratory wear investigation of resin posterior denture teeth. J Prosthet Dent 1992;67:812-4.

14. Vasconcelos LR, Consani RL, Mesquita MF, Sinhoreti MA. Effect of chemical and microwave disinfection on the surface microhardness of acrylic resin denture teeth. J Prosthodont 2013;22:298303.

15. Akar GC, Ergül S. The oral hygiene and denture status among residential home residents. Clin Oral Investig 2008;12:61-5.

16. De Sousa Porta SR, De Lucena-Ferreira SC, da Silva WJ, Del Bel Cury AA. Evaluation of sodium hypochlorite as a denture cleanser: a clinical study. Gerodontology $2013 ; 10: 1111$

17. Felton DA. Edentulism and comorbid factors. Tex Dent J 2010;127:389-401.

18. Lima EM, Moura JS, Del Bel Cury AA, Garcia RC, Cury JA. Effect of enzymatic and $\mathrm{NaOCl}$ treatments on acrylic roughness and on biofilm accumulation. J Oral Rehabil 2006;33:356-62.

19. Vieira AP, Senna PM, Silva WJ, Del Bel Cury AA. Long-term efficacy of denture cleansers in preventing Candida spp. biofilm recolonization on liner surface. Braz Oral Res 2010;24:342-8.

20. Anusavice KJ. Phillip's Science of dental materials, 11.ed, Philadelphia, Saunders, 2003, sayfa, 73-101

21. Kurtoglu C,Ekren O, Powers J.M, Kiat-amnuay S. Effect of Thixotropic Agent on the Mechanical Properties of Platinum-based Silicone Maxillofacial Elastomers Int J Anaplast 2009;3:11-6.

22. Whitman DJ, McKinney JE, Hinman RW, Hesby RA, Pelleu GB Jr. In vitro wear rates of three types of commercial denture tooth materials. J Prosthet Dent 1987;57:243-6.

23. Suzuki S,In vitro wear of nano-composite denture teeth. J Prosthodont 2004;13:238-43.
24. Assunção WG, Gomes EA, Barão VA, Barbosa DB, Delben JA, Tabata LF. Effect of storage in artificial saliva and thermal cycling on Knoop hardness of resin denture teeth. J Prosthodont Res 2010;54:123-7.

25. Campanha $\mathrm{NH}^{1}$, Pavarina AC, Jorge $\mathrm{JH}$, Vergani $\mathrm{CE}$, Machado AL, Giampaolo ET. The effect of longterm disinfection procedures on hardness property of resin denture teeth. Gerodontology 2012; 29: 571-6.

26. Pavarina $A C$, Vergani $C E$, Machado $A L$, Giampaolo ET, Teraoka MT. The effect of disinfectant solutions on the hardness of acrylic resin denture teeth. J Oral Rehabil 2003;30:749-52.

\section{Yazışma Adresi:}

Yrd.Doç.Dr.Orhun EKREN

Çukurova Üniversitesi Diş Hekimliği

Fakültesi Protetik Diş Ted. A.D Balcalı

Sarıçam/Adana

Tel: 0(533)7175954

e-mail: orhunekren@hotmail.com 